\title{
DE PLANTIS LEGIONENSIBUS. NOTA IV
}

\author{
E. HERNANDEZ HERNANDEZ
}

\begin{abstract}
RESUMEN: Como continuación de las precedentes aportaciones a la flora de León se citan diez nuevos taxones para el catálogo florístico de la provincia, señalando algunas caracteristicas ecológicas y corológicas de los mismos.
\end{abstract}

SUMAaRY: As following the former check-list apportations for León province. Ten taxa are recorded for the first time.

Chenopodium hybridum L., Sp. Pl. 219 (1753)

12).

LEON: Pío (Oseja de Sajambre) (30TUn37), 15. IX.1979, (LEB 218

En comunidades de Polygono-Chenopodion Koch. 1926 em. Sissingh. 1946.

Se ha mencionado de Asturias (cfr. Navarro Andrés, 1977; Tüxen \& Oberdorfer , 1958).

Chenopodium murale L., Sp. Pl. 219 (1753)

LEON: Lodares (Embalse del Porma) (30TUN15), 4.IX.1978, (LEB 08315); Nocedo (30TUN05), 5.X.1982, (LEB 17394). 1967.

En comunidades de Chenopodion muralis Br.-Bl. 1931 em. Bolós

Se conoce de Asturias (cfr. Díaz González, 1974-75; Chermezon, 1920) y Salamanca (cfr. Tüxen \& Oberdorfer, 1958; Ladero, Navarro \& Valle, 1983).

En la primera localidad recolectamos Hippocrepis glauca Ten, taxon poco conocido de la provincia ( $\mathrm{cfr}$. Pérez Morales, López Pacheco \& Puente García, 1983). De la misma localidad y sobre calizas recolectamos Teucrium polium L. subsp. expansum (Pau) Rivas Goday \& Borja. Señalada por Carbó, Mayor, Andrés \& Losa (1977).

Consolida ambigua (L.) P.W. Ball et Heywood, Feddes Repert. 66: 151 (1962)

LEON: Camposolillo (30TUN16), 22.VII.1974, (LEB 00592); Soto y 
Amio (30TTN64), 30.VII.1978, (LEB 06321); Benamariel (30TTU89), 15. VII.1977, (LEB 11548).

Conocida de Santander (cfr. Guinea, 1953).

En la primera localidad y en prados de siega de Cynosurion cristati Tx. 1947, recolectamos Fritillaria legionensis Llamas \& Andrés, endemismo Ubiñense.

Iberis tenoreana DC. var. lereschiana Barbey-Gamper, Bull. Soc. Bot. Genève 12: 240 (1920)

LEON: Pico Susarón (Puebla de Lillo) (30TUN16), 20.Vil.1977, (LEB 8460); Valdeteja (30TUN05), 23.V.1979, (LEB 16702); Pico Huevo (30TTN9765), 19.VII.1979, (LEB 16703).

Taxon conocido de los Picos de Europa (cfr. Arrieu, 1944; Fernández Prieto, 1982) y de Mortera del Coto (Somiedo, Asturias) (cfr. Fernández Prieto, 1981).

En la primera localidad recolectamos Carex disticha Hudson, no muy conocido en la provincia (cfr. Rivas-Martínez, 1976).

Raphanus raphanistrum L. subsp. microcarpus (Lange) Thell. in Hegi. III. Pl. Mitteleur. 4(1): 275 (1918)

LEON: Valdehuesa (30TUN15), 1.VIII.1977, (LEB 21804).

Sobre sustrato calizo de la mísma localidad recolectamos Jasonia tuberosa (L.) DC.

Sedum telephium L. subsp. fabaria (Koch.) Kirschleger, Fl. Alsace 1: 284 (1852)

LEON: Puebla de Lillo (30TUN16), 22.VIII.1978 (LEB 10180).

Recolectada sobre sustrato calizo.

Lathyrus montanus Bernh., Syst. Verz. Erfurt 247 (1800)

LEON: Rucayo (30TUN16), 25.VI.1976, (LEB 617). al. 1984 .

En melojares de Linario-Quercetum pyrenaicae Rivas-Martínez \&

Centaurea micrantha Hoffmanns \& Link subsp. herminii (Rouy) Dostál, Bot. Jour. Linn. Soc. 71: 199 (1976)

LEON: Valdehuesa (30TUN15), 1.VIII.1977, (LEB 21801).

Localidad relevante ya que era considerada como endemismo de la Sierra de la Estrella (Portugal) (cfr. Dostál, 1976).

Hieracium inuloides Tausch., Flora (Regensb.) 20 Ergänz. 1: 71 (1837)

LEON: Puebla de Lillo (30TUN16), 22.VII.1977 (LEB 21799).

En este taxon hemos incluido el material recolectado en hayedos del Luzulo henriquesii-Fagetum Rivas-Martínez \& al. 1984. 
Allium massaessylum Batt. \& Trabut, Bull. Soc. Bot. Fr. 39: 74 (1982)

LEON: Valle de Iyarga (Puebla de Lillo) (30TUN06), 6.VII.1977, (LEB 21086).

Recolectado sobre suelo arenoso y a una altitud de $1300 \mathrm{~m}$. Ampliamos el areal de este taxon, completando el mapa de su distribución (cfr. Pastor \& Valdés, 1983). La cita más próxima corresponde a la provincia de Salamanca (cfr. Casaseca, 1975).

\section{BIBLIOGRAFIA}

ARRIEU, F. -1944- Vegetation des Picos de Europa. Les paysages pastoraux. Bull. Soc. Hist. Nat. Toulouse, 75:359-375.

CARBO, R., MAYOR, M., ANDRES, J. \& LOSA, J.M. -1977-Aportaciones al catálogo florístico de la provincia de León.II. Acta Bot. Malacitana, 3: $63-120$.

CASASECA, B. -1975- Contribución al conocimiento de la Flora Salmantina. II. Anal. Inst. Bot. Cavanilles, 32(2): 255-258.

CHERMEZON, H. -1920- Aperçu sur le vegetation du littoral asturien. Bull. Soc. Linn. Normandie, 7a sér. ,3: 159-213.

DIAZ GONZALEZ, T.E. -1974 - 1975- Estudio de la vegetación del litoral occidental asturiano. Rev. Fac. Cienc. Oviedo, 16: 369-545.

DOSTAL, J. -1976- Centaurea L. in T.G. TUTIN \& al. (eds.). Flora Europaea, 4: 254-301.

FERNANDEZ PRIETO, J.A. -1981- Estudio de la Flora y Vegetación del Concejo de Somiedo. Tesis doctoral (inéd.). Fac. Ciencias de Oviedo.

FERNANDEZ PRIETO, J.A. -1982- Aspectos geobotánicos de la Cordillera Cantábrica. Anal. Jard. Bot. Madrid, 39(2):489-513.

GUINEA, E -1953- Geografía Botánica de Santander. Excma. Diputación Provincial de Santander.

LADERO, M., NAVARRO, F. \& VALLE, C.J. -1983- Comunidades nitrófilas salmantinas. Stvdia Botanica, 2: 7-67.

NAVARRO, F. -1977- Datos para el catálogo florístico del Aramo y sus estribaciones (Asturias).I. De Equisetaceae a Linariaceae. Bol. Inst. Est. Ast., ser. C, 22: 45-108.

PASTOR, J. \& VALDES, B. -1983- Revisión del Género Allium (Liliaceae) en la Península Ibérica e Islas Baleares. Publicaciones de la Univ. de Sevilla.

PEREZ MORALES, C., LOPEZ PACHECO, M.J. \& PUENTE, E. -1983- Algunos táxones de interés para la provincia de León. Stvdia Botanica, 2: 185189.

RIVAS-MARTINEZ, S. -1976- Notes systematiques, chorologiques et écologiques sur des plantes d'Espagne, 1. Candollea, 31: 111-117.

TUXEN, R. \& OBERDORFER, E. -1958- Eurosibirische Phanerogamen Gessellschaften Spaniens. Geobot. Ins. Rübel, 32: 1-328. 